\title{
Muscle architecture of the forelimb of the Golden Pheasant (Chrysolophus pictus) (Aves: Phasianidae) and its implications for functional capacity in flight
}

Yan Yang, Huan Wang and Zihui Zhang*

\begin{abstract}
Background: Flight is the central avian adaptation in evolution. Wing muscles form an important anatomical basis for avian flight, affecting wing performance and determine modes of flight. However, the roles of distal muscles in adjusting the wing, as well as their functional specializations, remain largely unknown. The importance of muscle fiber architecture has long been recognized. In this study, we provide quantitative anatomical data on the muscle architecture of the forelimb of the Golden Pheasant (Chrysolophus pictus), with an emphasis on brachial, antebrachial and manual segments.
\end{abstract}

Methods: The forelimbs of five Golden Pheasants were dissected and detailed measurements of all muscles were made, including muscle mass, muscle belly length, fascicle length. From these values, muscle volume, physiological cross-sectional area (PCSA) and maximum isometric force were derived.

Results: General trends such as the distribution of muscle mass, fascicle length and the ratio of tendon length/belly length are revealed. Comparing PCSAs between antebrachial depressors and elevators and between intrinsics of the alular digit and major digit yielded significant differences $(p<0.05)$. Pronounced development of the antebrachial depressors suggests that ventral rotation of the distal half of the wing is a pivotal factor in shape change and orientation modulation. Large PCSAs in tandem with the force generation capability of the major digit intrinsics may help stabilize the digits while enhancing support of the primary feathers. The architectural properties of the alular digit confirm that alular adjustment is essential to rapid adduction and abduction.

Conclusions: These observations illustrate the underlying structural basis for the functional capacities of the distal forelimb muscles and may provide additional information useful in further biomechanical and in vivo investigations.

Keywords: Architecture, Functional anatomy, Golden Pheasant, Wing muscles

\section{Background}

Flight is the central avian adaptation and an extraordinary range of specialized modes of flight has been exploited during evolution (Gill 1995). Skeleton and wing muscles form the basis for avian flight; these anatomical features are also adapted to reflect the flight style and phylogeny (McKitrick 1991; Corvidae et al. 2006). Muscle architecture and the physiological properties of muscle fiber are important in the evaluation of muscle capacity. With few exceptions, muscle mass and volume distribution are considered key physical parameters in avian myology, controlling flight (Fisher 1946;

\footnotetext{
*Correspondence: zihuizhang@cnu.edu.cn

College of Life Sciences, Capital Normal University, Beijing 100048, China
}

Owre 1967). Additional studies are needed to investigate the relationship between fiber-type distribution and muscle function (e.g., Meyers 1992; Torrella et al. 1998; Meyers and Stakebake 2005; Corvidae et al. 2006; Welch and Altshuler 2009). Mass, volume and the type of fiber substantially affect the contractile properties of a muscle. However, more than any other factor, muscle architecture predicts muscle function (Lieber and Fridén 2000; Ward et al. 2009; Lieber and Ward 2011). The importance of muscle fiber architecture has long been recognized and related studies have been widely reported in human and other mammals (Sacks and Roy 1982; Payne et al. 2005, 2006; Williams et al. 2007, 2008; Eng et al. 2008; Channon et al. 2009; Rupert et al. 2014), but 
seldom in birds. Report on the hind limb of an ostrich by Smith et al. (2006) may have been the first comprehensive research on avian muscle architecture. More work, with a special focus on the functional relationship between muscle architecture and flight styles, is needed (Dial 1992a).

Skeletal muscle architecture is defined as the arrangement of muscle fibers within a muscle (Gans 1982; Sacks and Roy 1982). The two most important architectural parameters are the physiological cross-sectional area (PCSA) and muscle fiber length (Lieber and Fridén 2000). The PCSA of a muscle is the only architectural parameter that is directly proportional to force generation, whereas muscle excursion and velocity are directly proportional to muscle fiber length. A greater serial sarcomere count (i.e., greater fiber length) leads directly to a larger muscle excursion, because serial excursions of individual sarcomeres are additive (Lieber and Ward 2011). Thus, long fibers are predicted to operate over a relatively wide range of muscle lengths, which can achieve greater velocities compared with shorter-fibered muscles. Due to these direct structure-function correlations, architectural features will undoubtedly reflect the functional properties and specializations of different muscles.

The pectoralis and supracoracoideus play dominant roles in bird flight and are the most widely studied of the forelimb muscles. Electromyographic (EMG) data indicate that intrinsic muscles of the wing contribute little additional mechanical power for flight, but are important in modulating wing orientation and controlling wing shape (Dial 1992a, 1992b; Biewener 2011). Due to the difficulty of in vivo force measurements for smaller muscles located more distally in the wing, the roles of these muscles in adjusting the wing, as well as their functional specializations, remain largely unknown (Biewener 2011). Given this circumstance, analysis of muscle architecture can play an important role in evaluating the role of muscles. China is particularly rich in pheasants and their relatives, with the result that these receive more attention than any other group. The Golden Pheasant (Chrysolophus pictus) is an endemic pheasant of China, but with their number decreasing (Lei and Lu 2006). The flight of this species, as well as that of other phasianids involves an explosive take-off followed by a rapid and swift flapping flight (Askew and Marsh 2002). Many investigations have focused on the power output and function of wing muscles during non-steady flight (Dial 1992a, 1992b; Tobalske and Dial 2000; Askew et al. 2001; Askew and Marsh 2002). In this study we have attempted to quantify forelimb muscles architecture in the Golden Pheasant, with an emphasis on the brachial, antebrachial and manual segments and their varying functions in adjusting wing shape. An understanding of muscle architectural specialization illuminates the functional features of the different muscles used during flight and may provide additional information for further biomechanical and in vivo investigations.

\section{Methods}

Five adult Golden Pheasants [three females, two males; mass $422 \pm 95.8 \mathrm{~g}$ (mean $\pm \mathrm{SD})$ ] were obtained from an accredited local farm for use in this study, killed by decapitation. The project was approved by the Animal Care and Ethics Committee of Capital Normal University. After the birds were sacrificed, each limb was skinned and individual muscles were identified, exposed and cleared of fascia. The muscles were then systematically removed and detailed dissections of muscle-tendon architecture were carried out. Muscle architecture was determined from methods described by Smith et al. (2006). Muscle mass measurements were obtained with an electronic scale (Ohaus, USA) to the nearest $0.0001 \mathrm{~g}$, while lengths were measured with digital calipers (Workzone, Germany) to the nearest $0.01 \mathrm{~mm}$. Muscle belly length was measured as the length from the most proximal fibers to the most distal fibers. Muscle volume was calculated by dividing muscle mass by muscle density (1.06 g. $\mathrm{cm}^{-3}$; Mendez and Keys 1960; Brown et al. 2003) and its physiological cross-sectional area (PCSA) was then determined by dividing muscle volume by its mean fascicle length. To obtain fascicle length, the collagen between the muscle fibers was gradually dissolved in nitric acid $\left(30 \% \mathrm{HNO}_{3}\right)$ for about $24 \mathrm{~h}$ and then the tissue was immersed in a $50 \%$ glycerol solution. At least five measurements of fascicle length were taken from randomly distributed areas and depths within the muscle belly. The maximum isometric force of a muscle, $F_{\max }$, was estimated by multiplying PCSA by the maximum isometric stress of a vertebrate skeletal muscle (0.3 MPa; Wells 1965). Pennation angles were not included in our measurements, because muscle bellies in most of the forelimb muscles are directly attached to the skeleton, without forming tendons of insertion. As well, among muscles with an insertion tendon, nearly all angles are smaller than $10^{\circ}$; the cosine of a $10^{\circ}$ angle is very close to one and would thus have little effect on estimations of PCSA.

For gross comparison, muscles were assigned to six functional groups: i.e., brachial depressors/elevators, antebrachial extensors/flexors, antebrachial depressors/elevators, manual extensors/flexors, manual depressors/ elevators and manual intrinsics. For each functional muscle group, the sum of the separate muscle PCSAs and the total force were combined to result in one value for each group; the fascicle length was averaged among the containing muscles of that group. One way ANOVA was performed within each functional group. Functions of individual muscles have not been previously published for 
this species and are, therefore, based on anatomical positioning, our personal observations and references from George and Berger (1966).

\section{Results}

\section{General features}

All 47 previously recognized muscles (Zhang and Yang 2013) were identified in the pectoral limb of the Golden Pheasant. The corresponding architectural data are presented in Table 1. On average, the unilateral forelimb muscle mass of the Golden Pheasant accounts for $12.00 \% \pm 1.56 \%$ (mean $\pm \mathrm{SD}$ ) of body mass, corresponding to $51.74 \mathrm{~g}$ of muscle per forelimb. Muscles were assigned to four groups according to their location; the distribution of muscle mass exhibited a sharp reduction from the proximal to the distal (Figure 1). Extrinsic muscles, brachial muscles, antebrachial muscles and manual muscles constitute $84.98 \%, 8.81 \%, 5.94 \%$ and $0.33 \%$, respectively, of the total forelimb muscle mass. The pectoralis (PT), supracoracoideus (SP) and scapulohumeralis caudalis (SHC) are the three largest muscles of the forelimb. PT accounts for $13.4 \%$ of the total body mass and $55.86 \%$ of the total forelimb muscle mass. The corresponding data for SP are $3.9 \%$ and $16.31 \%$ and for SHC $1.3 \%$ and $5.33 \%$. The largest brachial muscle was triceps brachii, accounting for $4.63 \%$ of the total forelimb muscle mass, closely followed by biceps brachii (BB, 1.66\%) and deltoideus major (DMA, 1.41\%). Triceps brachii is composed of two distinct heads, the humeral and scapular, with the humeral head (TH, $1.331 \pm 0.490 \mathrm{~g}$ ) slightly larger than the scapular head (TS, $1.076 \pm 0.439 \mathrm{~g}$ ). The extensor metacarpi radialis (EMR) and flexor carpi ulnaris (FCU) muscles form the bulk of the antebrachial group, weighing $0.614 \pm 0.284 \mathrm{~g}$ and $0.469 \pm 0.293 \mathrm{~g}$, respectively, corresponding to 1.17 and $0.87 \%$ of the total forelimb muscle mass. Smallest were the distal manual muscles, which include the flexor alulae (FA, $0.004 \pm 0.002 \mathrm{~g}, 0.008 \%$ ), the extensor brevis alulae (EBA, $0.007 \pm 0.005 \mathrm{~g}, 0.014 \%$ ) and the flexor digiti minoris (FDMI, $0.011 \pm 0.006 \mathrm{~g}$, $0.020 \%)$.

Among muscles with an insertion tendon, tendon lengths were obtained only from those that were discernible. The proportional lengths of muscle belly and tendon lengths are shown in Figure 2. Most tendons in the distal limb are comparatively longer than those in the proximal limb and exceed belly lengths.

The distribution of fascicle lengths showed a general trend, with proximal muscles having longer fascicles and distal muscles relatively short fascicles. The pectoralis and supracoracoideus had the longest mean fascicle lengths $(2.44 \mathrm{~cm}$ and $2.33 \mathrm{~cm}$, respectively), followed closely by the latissimus dorsi, deltoideus major, tensor propatagialis and scapulohumeralis caudalis. Intrinsic manual muscles displayed the shortest fascicle lengths, ranging from 0.16 to $0.44 \mathrm{~cm}$. Among the intrinsics, the abductor and adductor of the alular digit were relatively high in this parameter.

The pectoralis muscle had, on average, the largest PCSA $\left(11.15 \mathrm{~cm}^{2}\right)$, thus yielding the highest forceproducing capacity of all the forelimb muscles $\left(F_{\max }=\right.$ $334.55 \mathrm{~N})$, followed by the supracoracoideus $\left(3.63 \mathrm{~cm}^{2}\right.$, $108.95 \mathrm{~N}$ ). PCSAs of most of the intrinsics of the manus, i.e., latissimus dorsi pars cranialis, scapulohumeralis cranialis, serratus superficialis pars cranialis and brachialis, were the smallest, at less than $0.1 \mathrm{~cm}^{2}$.

\section{Comparisons between functional groups}

The fascicle length and PCSA of six functional groups are shown in Table 2. A significant difference $(p<0.05)$ was observed between the antebrachial depressors and elevators for PCSA and total force. The difference in PCSA and total force between the intrinsics of the alular digit and major digit was also significant $(p<0.05)$.

Disparities in architectural properties and mechanical function within a synergic group, or between different functional groups, are shown in Figure 3. The antebrachial extensors were characterized by high force-producing capacities, whereas the flexors showed more diversification in their fundamental design: FCU and BB would be expected to govern function because of their large PCSAs, while TP has the capacity to perform a large excursion. Considering the depressors (or pronators) vs. elevators (supinators) comparison, the other antagonistic groups of the antebrachium, the former possessed a significantly larger PCSA and relatively longer FL than the latter. The FCU appeared to control the flexion of the manus in force production. Extension of the manus tended to be more complicated than flexion for simultaneously possessing a large PCSA muscle (EMR) and a long FL muscle (ELA), features that suggest a design predicated on both force and speed. All intrinsic muscles of the manus are indicated on the bottom of the left-hand side of Figure 3 (low PCSA, short fascicles). They differ anatomically in that the muscles of the major digit are characterized by large PCSAs, whereas the muscles in the alular digit are remarkable for their long fascicle lengths.

\section{Discussion and conclusions}

Along with certain mammals and birds, such as horses and ostriches (Payne et al. 2005; Smith et al. 2006), the distribution of muscle mass throughout the Golden Pheasant forelimb demonstrated a proximal-to-distal reduction. This design minimizes the moment of inertia during locomotion (Hildebrand 1988), which, in turn, conserves metabolic energy (Steudel 1996). The tendon in the distal forelimb segment of the Golden Pheasant was relatively longer than that found in the proximal. 
Table 1 Architectural properties of forelimb muscles in the Golden Pheasant

\begin{tabular}{|c|c|c|c|c|c|c|c|}
\hline Muscle & Abbreviation & $\begin{array}{l}\text { Muscle } \\
\text { mass (g) }\end{array}$ & $\begin{array}{l}\text { Fascicle } \\
\text { length }(\mathrm{cm})\end{array}$ & $\begin{array}{l}\text { Belly } \\
\text { length }(\mathrm{cm})\end{array}$ & $\begin{array}{l}\text { Volume } \\
\left(\mathrm{cm}^{3}\right)\end{array}$ & $\begin{array}{l}\text { PCSA } \\
\left(\mathrm{cm}^{2}\right)\end{array}$ & Force $(\mathrm{N})$ \\
\hline M. pectoralis & PT & $28.830 \pm 10.956$ & $2.439 \pm 0.155$ & $9.216 \pm 3.200$ & 27.198 & 11.152 & 334.552 \\
\hline M. supracoracoideus & SC & $8.495 \pm 3.547$ & $2.330 \pm 0.601$ & $10.141 \pm 0.520$ & 8.014 & 3.632 & 108.951 \\
\hline M. scapulohumeralis caudalis & $\mathrm{SHC}$ & $2.771 \pm 1.143$ & $1.686 \pm 0.480$ & $4.676 \pm 0.506$ & 2.614 & 1.611 & 48.334 \\
\hline M. coracobrachialis caudalis & $\mathrm{CBC}$ & $1.101 \pm 0.397$ & $1.031 \pm 0.321$ & $3.582 \pm 0.342$ & 1.039 & 1.065 & 31.954 \\
\hline M. subcoracoideus & SUC & $0.985 \pm 0.396$ & $1.192 \pm 0.382$ & $2.844 \pm 0.473$ & 0.929 & 0.858 & 25.753 \\
\hline M. subscapularis & SS & $0.177 \pm 0.065$ & $0.487 \pm 0.056$ & $1.434 \pm 0.244$ & 0.167 & 0.339 & 10.177 \\
\hline M. latissimus dorsi pars cranialis & LDCR & $0.126 \pm 0.029$ & $2.080 \pm 0.351$ & $3.245 \pm 0.486$ & 0.119 & 0.058 & 1.729 \\
\hline M. latissimus dorsi pars caudalis & LDCA & $0.387 \pm 0.203$ & $2.238 \pm 0.212$ & $3.237 \pm 0.396$ & 0.365 & 0.162 & 4.870 \\
\hline M. rhomboideus superficialis & RS & $0.247 \pm 0.115$ & $0.773 \pm 0.204$ & $1.100 \pm 0.215$ & 0.233 & 0.291 & 8.742 \\
\hline M. rhomboideus profundus & $\mathrm{RP}$ & $0.263 \pm 0.139$ & $0.670 \pm 0.189$ & $0.730 \pm 0.095$ & 0.248 & 0.359 & 10.755 \\
\hline $\begin{array}{l}\text { M. serratus superficialis pars } \\
\text { caudalis }\end{array}$ & SSC & $0.217 \pm 0.081$ & $0.914 \pm 0.213$ & $1.796 \pm 0.273$ & 0.205 & 0.232 & 6.956 \\
\hline $\begin{array}{l}\text { M. serratus superficialis pars } \\
\text { metapatagialis }\end{array}$ & SSM & $0.123 \pm 0.031$ & $4.044 \pm 0.643$ & $5.222 \pm 0.814$ & 0.116 & 0.029 & 0.866 \\
\hline M. serratus profundus & $\mathrm{SP}$ & $0.067 \pm 0.031$ & $0.566 \pm 0.144$ & $0.795 \pm 0.277$ & 0.063 & 0.115 & 3.436 \\
\hline M. scapulohumeralis cranialis & $\mathrm{SHA}$ & $0.017 \pm 0.004$ & $0.560 \pm 0.243$ & $0.968 \pm 0.298$ & 0.016 & 0.031 & 0.935 \\
\hline M. sternocoracoideus & STC & $0.073 \pm 0.059$ & $0.396 \pm 0.021$ & $0.600 \pm 0.118$ & 0.068 & 0.171 & 5.142 \\
\hline $\begin{array}{l}\text { M. serratus superficialis pars } \\
\text { cranialis }\end{array}$ & SSA & $0.047 \pm 0.015$ & $1.113 \pm 0.221$ & $1.810 \pm 0.351$ & 0.044 & 0.040 & 1.191 \\
\hline M. triceps brachii humeral head & $\mathrm{TH}$ & $1.331 \pm 0.490$ & $1.220 \pm 0.137$ & $5.173 \pm 0.277$ & 1.256 & 1.022 & 30.672 \\
\hline M. triceps brachii scapular head & TS & $1.076 \pm 0.439$ & $1.503 \pm 0.390$ & $5.250 \pm 0.298$ & 1.015 & 0.675 & 20.236 \\
\hline M. biceps brachii & BB & $0.850 \pm 0.449$ & $1.293 \pm 0.772$ & $4.048 \pm 0.670$ & 0.802 & 0.846 & 25.387 \\
\hline M. deltoideus major & DMA & $0.719 \pm 0.254$ & $2.174 \pm 0.120$ & $3.910 \pm 0.346$ & 0.678 & 0.316 & 9.478 \\
\hline M. tensor propatagialis & $\mathrm{TP}$ & $0.398 \pm 0.176$ & $2.009 \pm 0.228$ & $2.860 \pm 0.248$ & 0.375 & 0.204 & 6.112 \\
\hline M. deltoideus minor & DMl & $0.062 \pm 0.017$ & $0.460 \pm 0.141$ & $0.983 \pm 0.246$ & 0.058 & 0.136 & 4.069 \\
\hline M. expansor secondariorum & ES & $0.057 \pm 0.020$ & $0.277 \pm 0.083$ & $0.654 \pm 0.076$ & 0.054 & 0.195 & 5.836 \\
\hline M. brachialis & BR & $0.038 \pm 0.009$ & $0.640 \pm 0.163$ & $1.239 \pm 0.272$ & 0.036 & 0.058 & 1.732 \\
\hline M. extensor metacarpi radialis & EMR & $0.614 \pm 0.284$ & $0.871 \pm 0.148$ & $3.981 \pm 0.243$ & 0.580 & 0.648 & 19.426 \\
\hline M. pronator superficialis & PS & $0.351 \pm 0.112$ & $0.644 \pm 0.097$ & $3.550 \pm 0.079$ & 0.332 & 0.509 & 15.282 \\
\hline M. pronator profundus & PP & $0.297 \pm 0.101$ & $0.915 \pm 0.332$ & $2.997 \pm 0.294$ & 0.280 & 0.326 & 9.772 \\
\hline M. flexor carpi ulnaris & FCU & $0.469 \pm 0.293$ & $0.541 \pm 0.092$ & $3.670 \pm 0.157$ & 0.442 & 0.804 & 24.129 \\
\hline M. flexor digitorum profundus & FDP & $0.251 \pm 0.091$ & $0.874 \pm 0.236$ & $3.541 \pm 0.289$ & 0.237 & 0.283 & 8.477 \\
\hline M. extensor carpi ulnaris & ECU & $0.172 \pm 0.067$ & $0.642 \pm 0.114$ & $3.421 \pm 0.257$ & 0.163 & 0.263 & 7.897 \\
\hline M. ectepicondylo ulnaris & ECTU & $0.205 \pm 0.079$ & $0.507 \pm 0.280$ & $4.223 \pm 0.230$ & 0.193 & 0.501 & 15.023 \\
\hline M. extensor longus alulae & ELA & $0.158 \pm 0.067$ & $1.440 \pm 0.566$ & $3.949 \pm 0.277$ & 0.149 & 0.104 & 3.135 \\
\hline M. supinator & SU & $0.089 \pm 0.034$ & $0.410 \pm 0.083$ & $2.485 \pm 0.485$ & 0.084 & 0.201 & 6.035 \\
\hline M. extensor longus digiti majoris & ELDM & $0.088 \pm 0.037$ & $0.819 \pm 0.244$ & $2.406 \pm 0.270$ & 0.083 & 0.101 & 3.025 \\
\hline M. entepicondylo ulnaris & ENU & $0.077 \pm 0.042$ & $0.395 \pm 0.114$ & $2.166 \pm 0.181$ & 0.072 & 0.185 & 5.552 \\
\hline M. ulnometacarpalis ventralis & UV & $0.092 \pm 0.032$ & $0.780 \pm 0.196$ & $2.259 \pm 0.296$ & 0.087 & 0.118 & 3.542 \\
\hline M. ulnometacarpalis dorsalis & UD & $0.076 \pm 0.026$ & $0.663 \pm 0.134$ & $1.245 \pm 0.359$ & 0.071 & 0.106 & 3.179 \\
\hline M. extensor digitorum communis & EDC & $0.070 \pm 0.024$ & $0.790 \pm 0.164$ & $3.163 \pm 0.184$ & 0.066 & 0.084 & 2.532 \\
\hline M. flexor digitorum superficialis & FDS & $0.063 \pm 0.017$ & $0.654 \pm 0.014$ & $1.809 \pm 0.244$ & 0.060 & 0.091 & 2.739 \\
\hline M. abductor digiti majoris & ABDM & $0.043 \pm 0.025$ & $0.259 \pm 0.056$ & $2.098 \pm 0.198$ & 0.041 & 0.157 & 4.712 \\
\hline M. interosseus dorsalis & ID & $0.034 \pm 0.009$ & $0.271 \pm 0.074$ & $1.430 \pm 0.203$ & 0.032 & 0.120 & 3.613 \\
\hline
\end{tabular}


Table 1 Architectural properties of forelimb muscles in the Golden Pheasant (Continued)

\begin{tabular}{|c|c|c|c|c|c|c|c|}
\hline M. interosseus ventralis & IV & $0.027 \pm 0.015$ & $0.282 \pm 0.116$ & $1.482 \pm 0.273$ & 0.025 & 0.095 & 2.836 \\
\hline M. abductor alulae & $\mathrm{ABA}$ & $0.034 \pm 0.019$ & $0.436 \pm 0.158$ & $0.999 \pm 0.183$ & 0.032 & 0.080 & 2.410 \\
\hline M. adductor alulae & ADA & $0.012 \pm 0.004$ & $0.390 \pm 0.180$ & $0.626 \pm 0.135$ & 0.012 & 0.034 & 1.011 \\
\hline M. extensor brevis alulae & EBA & $0.007 \pm 0.005$ & $0.243 \pm 0.116$ & $0.537 \pm 0.055$ & 0.007 & 0.030 & 0.905 \\
\hline M. flexor alulae & FA & $0.004 \pm 0.002$ & $0.198 \pm 0.048$ & $0.428 \pm 0.185$ & 0.004 & 0.020 & 0.589 \\
\hline M. flexor digiti minoris & FDMI & $0.011 \pm 0.006$ & $0.164 \pm 0.032$ & $1.588 \pm 0.344$ & 0.010 & 0.064 & 1.912 \\
\hline
\end{tabular}

This extra length enables muscles to control distal movements of the wing without the burden of extra muscle mass. Possessing a small and lightweight distal segment (Biewener 2011) provides a distinct advantage by decreasing limb inertia during flight. The ability of tendons to stretch and recoil enables storage and recovery of elastic energy, while allowing muscle fibers to

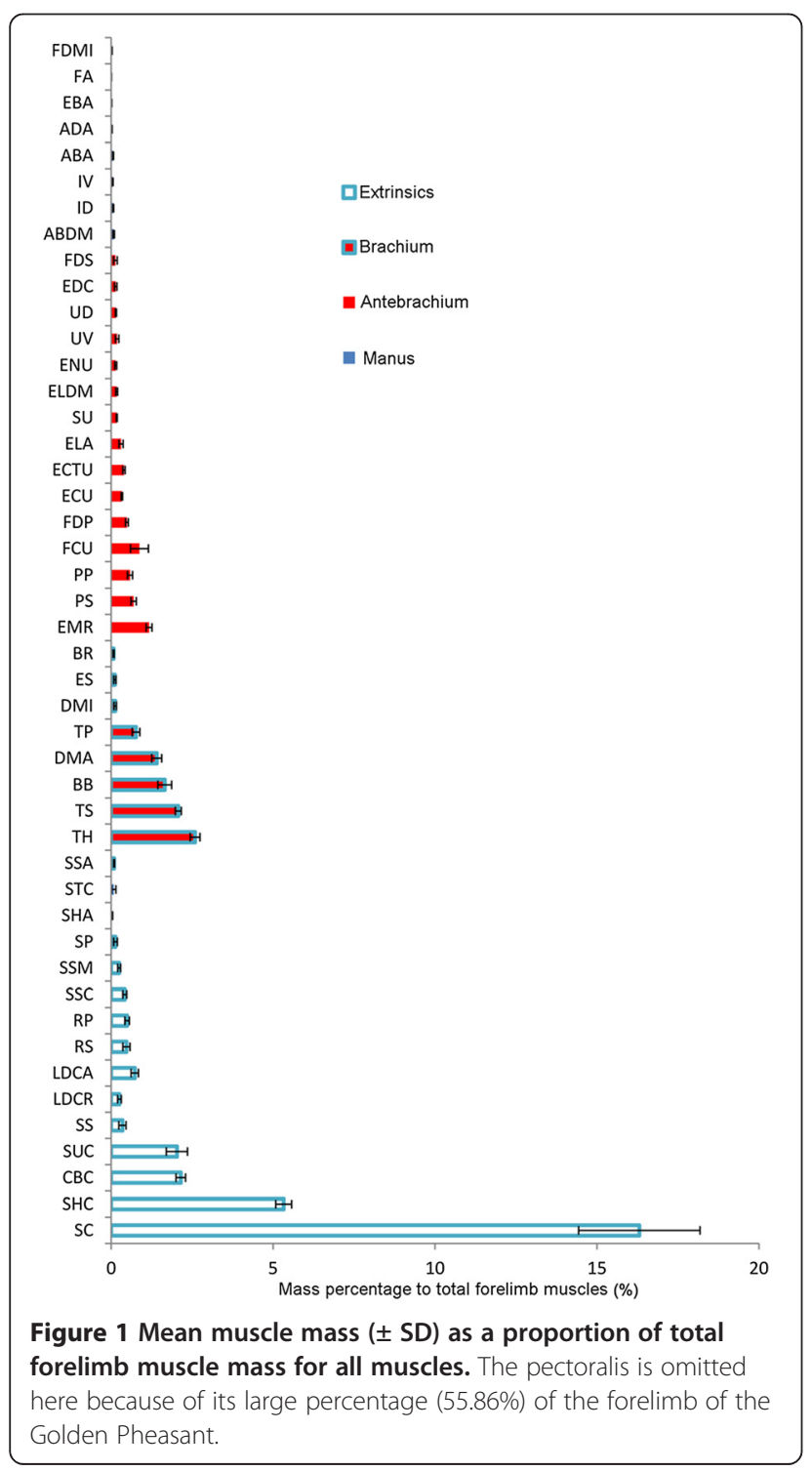

sustain high forces (Roberts 2002). Longer tendons in the distal forelimb enhance muscle performance by increasing contraction efficiency and reducing metabolic costs.

As the primary wing depressor and elevator, the pectoralis and supracoracoideus are the most widely studied of the forelimb muscles. In the Golden Pheasant, these two muscles possess the largest mass, PCSA and proportion of all the muscles in the forelimb. As expected, they also possess the longest fascicle lengths. Greenwalt (1962) predicted that the pectoralis muscle of a volant species should constitute $15.5 \%$ of the total body mass of a bird. In the Golden Pheasant, this muscle comprises $13.4 \%$ of total body mass. Regarding the supracoracoideus, this muscle represents about $1.6 \%$ of the total body mass in volant birds and most non-diving birds, 4\%-5\% in wing-propelled diving birds (e.g., Atlantic Puffin) and $10 \%-12 \%$ in penguins (Greenwalt 1962; Poore et al. 1997; Kovacs and Meyers 2000). Our results show that the supracoracoideus in the Golden Pheasant accounts for $3.9 \%$ of the total body mass of this species. The relatively large supracoracoideus in alcids and other wingpropelled diving birds most likely evolved to raise the wing against the resistive drag of water (Kovacs and Meyers 2000). The pheasants use high-frequency, highamplitude wing beats during their explosive take-off flights and these attributes probably create a high inertial

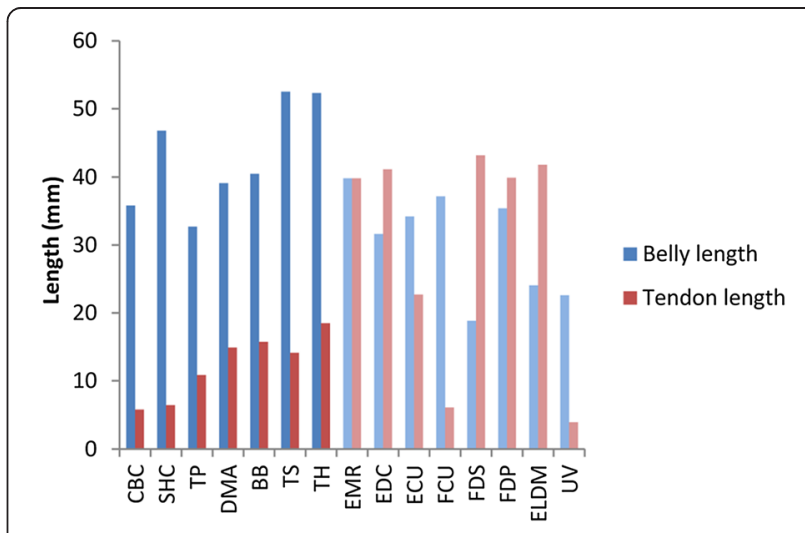

Figure 2 Comparison between tendon length and muscle belly length for both the proximal (dark red and dark blue) and distal (light red and light blue) forelimb muscles of the Golden Pheasant. 
Table 2 Comparisons of muscle group architecture

\begin{tabular}{llcc}
\hline Functional group & Mean FL $(\mathbf{c m})$ & Total PCSA $\left(\mathbf{c m}^{\mathbf{2}}\right)$ \\
\hline Brachium & Depressors & 1.815 & 12.010 \\
\multirow{3}{*}{ Antebrachium } & Elevators & 1.662 & 5.694 \\
& Extensors & 1.088 & 2.501 \\
\multirow{3}{*}{ Antebrachium } & Flexors & 0.999 & 2.823 \\
& Depressors & 0.688 & 1.336 \\
\multirow{3}{*}{ Manus } & Elevators & 0.402 & 0.386 \\
& Flexors & 0.692 & 1.665 \\
Manus & Extensors & 0.980 & 0.937 \\
& Depressors & 0.465 & 0.466 \\
Intrinsics & Elevators & 0.629 & 0.321 \\
& Alular digit & 0.317 & 0.164 \\
& Major digit & 0.271 & 0.372 \\
& Minor digit & 0.164 & 0.064
\end{tabular}

power requirement for elevating the wing. In the Golden Pheasant, it is likely that the supracoracoideus is large to meet this inertial-work or inertial-power requirement. A long fascicle results in greater excursion length, whereas PCSA corresponds to force production. The long fascicle and large PCSA of the pectoralis and supracoracoideus enable powerful upstrokes and downstrokes through a large excursion to achieve sufficient aerodynamic lift, particularly during takeoff and vertical ascending flights (Biewener 2011).

Previous work (Dial 1992a; Berg and Biewener 2010) demonstrated that the brachial and antebrachial muscles act primarily as joint stabilizers and are not essential for normal extension and flexion of the wing during level flapping flights. However, during non-steady flights (e.g., takeoffs and landings), these muscles contribute to the performance of the wing by acting as an aerofoil, modulating wing orientation and wing shape (Dial 1992a, 1992b; Biewener 2011). In this study, we have demonstrated differences in architectural design within antagonistic groups of the antebrachial muscles (Table 2). For example, antebrachial elevators vs. depressors present significant differences in total PCSA and estimated isometric force $(p<0.05)$. Similar differences were also observed between intrinsic muscles of the major and alular digits, which have architectural features that facilitate force production (major digits) and excursion (alular digit). Pronounced development of the antebrachial depressors (pronator superficialis, pronator profundus and

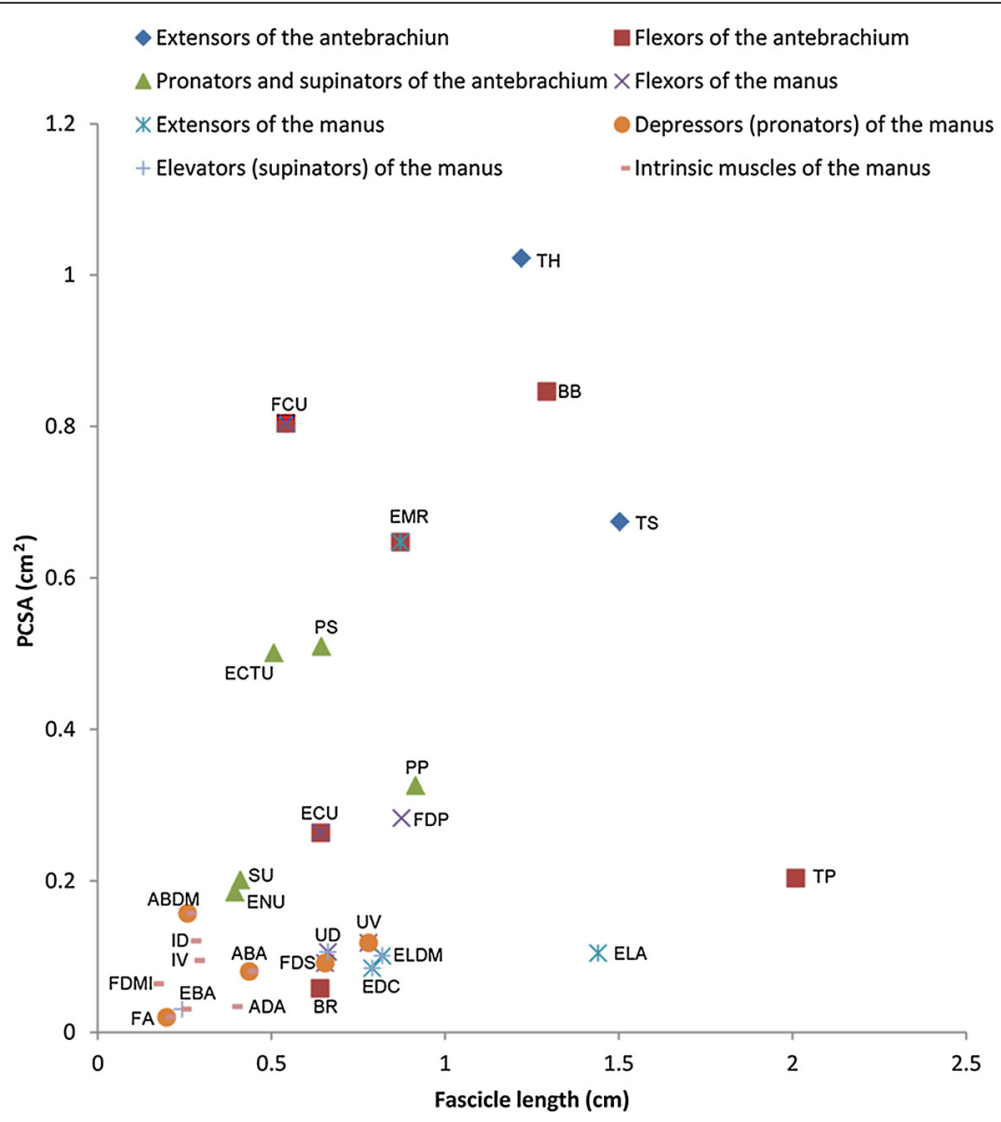

Figure 3 Scatter graph of fascicle length and physiological cross-sectional areas (PCSAs) of muscles in the forelimb of the Golden Pheasant. 
ectepicondylo ulnaris) suggests that ventrally rotating the distal half of the wing should profoundly affect shape change and orientation modulation during non-steady flights; these muscles are evidently capable of providing increased thrust for acceleration during takeoff and vertical ascending flights (Biewener 2011). A similar trend was also found in pigeons, where the pronator superficialis exhibited biphasic activities with EMG intensities at their maximum during takeoff and ascending flights (Dial 1992b). Three birds of prey (Cooper's Hawk Accipiter cooperii, Osprey Pandion haliaetus and Red-tailed Hawk Buteo jamaicensis) also exhibit these muscle-induced phenomena, which may explain observed differences in flight mode and hunting behavior (Corvidae et al. 2006). The manus intrinsics (Figure 3) may be related to joint stabilization or the execution of precision movements (Williams et al. 2008; Channon et al. 2009). The major digit provides support for the outer primaries that control forward thrust and aerodynamic performance, particularly during flapping flights (Combes and Daniel 2001; Swaddle and Lockwood 2003). The major digit intrinsics, with their greater PCSAs and force generation capability, may help stabilize the wing and provide powerful support for the primary feathers. The alula, or bastard wing, is a high lift device located at the leading edge of the wing that allows birds to fly at an acute attack angle and at a lower speed without stalling (Gill 1995; Alvarez et al. 2001). It features 3 to 5 small flight feathers originating from the first digit and moves independently of the rest of the wingtip. Four muscles attach to the alular digit and control the position of the alula; among them, the adductor and abductor appear to be dominant and more effective functionally due to their significantly longer fascicles. Their architectural properties are designed for excursion and velocity, as muscles with relatively long fibers operate over a large range of muscle lengths and can achieve faster velocities compared with a shorterfibered muscle (Ward et al. 2009). This may imply that adjustment of the alula is paramount for rapid adduction and abduction during flight in the Golden Pheasant.

Our results also revealed that muscle architecture varies widely within synergic groups (Figure 3, Table 2). The flexors of the manus, for example, are composed of six different muscles: i.e., flexor carpi ulnaris, flexor digitorum profundus, flexor digitorum superficialis, extensor carpi ulnaris, ulnometacarpalis ventralis and ulnometacarpalis dorsalis. They all contribute to flexion of the manus. The flexor carpi ulnaris (FCU), with the largest PCSA at nearly 8 times that of the flexor digitorum superficialis, generates very high forces and acts as the functionally dominant muscle in this group. Within the manual extensors group, extensor metacarpi radialis was designed for optimal force production, whereas extensor longus alulae evolved for fast velocity. These results are consistent with Dial's observation (1992a) that the extensor metacarpi radialis and flexor carpi ulnaris exhibited their greatest EMG activity during non-steady flights, indicating that the manus extension is significantly more complicated than flexion.

\section{Competing interests}

The authors declare that they have no competing interests.

\section{Authors' contributions}

$Z Z$ designed the experiments, and $Y Y$ and HW conducted the experiments. $Z Z, H W$ and $Y Y$ analyzed the data and wrote the paper. All authors read and approved the final manuscript.

\section{Acknowledgments}

We thank Guangdi Si for her help with laboratory work. This work was supported by the National Natural Science Foundation of China (30870263, 31272259).

Received: 14 August 2014 Accepted: 22 January 2015

Published online: 01 March 2015

\section{References}

Alvarez JC, Meseguer J, Pérez A (2001) On the role of the alula in the steady flight of birds. Ardeola 48:161-173

Askew GN, Marsh RL (2002) Muscle designed for maximum short-term power output: quail flight muscle. J Exp Biol 205:2153-2160

Askew GN, Marsh RL, Ellington CP (2001) The mechanical power output of the flight muscles of blue-breasted quail (Coturnix chinensis) during take-off. J Exp Biol 204:3601-3619

Berg AM, Biewener AA (2010) Wing and body kinematics of takeoff and landing flight in the pigeon (Columba livia). J Exp Biol 213:1651-1658

Biewener AA (2011) Muscle function in avian flight: achieving power and control. Phil Trans R Soc B 366:1496-1506

Brown NAT, Pandy MG, Kawcak CE, Mcilwraith CW (2003) Force- and moment-generating capacities of muscles in the distal forelimb of the horse. J Anat 203:101-113

Channon AJ, Günther MM, Crompton RH, Vereecke EE (2009) Mechanical constraints on the functional morphology of the gibbon hind limb. J Anat 215:383-400

Combes SA, Daniel TL (2001) Shape, flapping and flexion: wing and fin design for forward flight. J Exp Biol 204:2073-2085

Corvidae EL, Bierregaard RO, Peters SE (2006) Comparison of wing morphology in three birds of prey: correlations with differences in flight behavior. J Morphol 267:612-622

Dial KP (1992a) Avian forelimb muscles and nonsteady flight: can birds fly without using the muscles in their wings? Auk 109:874-885

Dial KP (1992b) Activity patterns of the wing muscles of the pigeon (Columba livia) during different modes of flight. J Exp Zool 262:357-373

Eng CM, Smallwood LH, Rainiero MP, Lahey M, Ward SR, Lieber RL (2008) Scaling of muscle architecture and fiber types in the rat hindlimb. J Exp Biol 211:2336-2345

Fisher HI (1946) Adaptations and comparative anatomy of the locomotor apparatus of New World vultures. Am Midl Nat 35:545-727

Gans C (1982) Fiber architecture and muscle function. Exercise Sport Sci Rev 10:160-207

George JC, Berger AJ (1966) Avian myology. Academic, New York

Gill FB (1995) Ornithology, 2nd edn. W. H. Freeman, New York

Greenwalt CH (1962) Dimensional relationships for flying animals. Smithson Misc Coll 144:1-46

Hildebrand M (1988) Form and function in vertebrate feeding and locomotion. Am Zool 28:727-738

Kovacs CE, Meyers RA (2000) Anatomy and histochemistry of flight muscles in a wing-propelled diving bird, the Atlantic Puffin, Fratercula arctica. J Morphol 244:109-125

Lei FM, Lu TC (2006) China endemic birds. Science Press, Beijing

Lieber RL, Fridén J (2000) Functional and clinical significance of skeletal muscle architecture. Muscle Nerve 23:1647-1666

Lieber RL, Ward SR (2011) Skeletal muscle design to meet functional demands. Phil Trans R Soc B 366:1466-1476 
McKitrick MC (1991) Forelimb myology of loons (Gaviiformes), with comments on the relationship of loons and tubenoses (Procellariiformes). Zool J Linn Soc 102:115-152

Mendez J, Keys A (1960) Density and composition of mammalian muscle. Metabolism 9:184-188

Meyers RA (1992) The morphological basis of folded-wing posture in the American Kestrel, Falco sparverius. Anat Rec 232:493-498

Meyers RA, Stakebake EF (2005) Anatomy and histochemistry of spread-wing posture in birds. 3. immunohistochemistry of flight muscles and the "shoulder lock" in albatrosses. J Morphol 263:12-29

Owre OT (1967) Adaptations for locomotion and feeding in the Anhinga and the Double-crested Cormorant. Ornithol Monographs 6:1-138

Payne RC, Hutchinson JR, Robilliard JJ, Smith NC, Wilson AM (2005) Functional specialisation of pelvic limb anatomy in horses (Equus caballus). J Anat 206:557-574

Payne RC, Crompton RH, Isler K, Savage R, Vereecke EE, Günther MM, Thorpe SKS, D'Août K (2006) Morphological analysis of the hindlimb in apes and humans. I. Muscle architecture. J Anat 208:709-724

Poore SO, Ashcroft A, Sánchez-Haiman A, Goslow GE Jr (1997) The contractile properties of the M. supracoracoideus in the pigeon and starling: a case for long-axis rotation of the humerus. J Exp Biol 200:2987-3002

Roberts TJ (2002) The integrated function of muscles and tendons during locomotion. Comp Biochem Phys A 133:1087-1099

Rupert JE, Rose JA, Organ JM, Butcher MT (2014) Forelimb muscle architecture and myosin isoform composition in the groundhog (Marmota monax). J Exp Biol. doi:10.1242/jeb.107128

Sacks RD, Roy RR (1982) Architecture of the hindlimb muscles of cats: functional significance. J Morphol 173:185-195

Smith NC, Wilson AM, Jespers KJ, Payne RC (2006) Muscle architecture and functional anatomy of the pelvic limb of the ostrich (Struthio camelus). Anat 209:765-779

Steudel K (1996) Limb morphology, bipedal gait, and the energetics of hominid locomotion. Am J Phys Anthropol 99:345-355

Swaddle JP, Lockwood R (2003) Wingtip shape and flight performance in the European Starling Sturnus vulgaris. Ibis 145:457-464

Tobalske BW, Dial KP (2000) Effects of body size on take-off flight performance in the Phasianidae (Aves). J Exp Biol 203:3319-3332

Torrella JR, Fouces V, Palomeque J, Viscor G (1998) Comparative skeletal muscle fibre morphometry among wild birds with different locomotor behaviour. J Anat 192:211-222

Ward SR, Eng CM, Smallwood LH, Lieber RL (2009) Are current measurements of lower extremity muscle architecture accurate? Clin Orthop Relat Res 467:1074-1082

Welch KC, Altshuler DL (2009) Fiber type homogeneity of the flight musculature in small birds. Comp Biochem Phys B 152:324-331

Wells JB (1965) Comparison of mechanical properties between slow and fast mammalian muscle. J Physiol 178:252-269

Williams SB, Wilson AM, Payne RC (2007) Functional specialisation of the thoracic limb of the hare (Lepus europeus). J Anat 210:491-505

Williams SB, Wilson AM, Rhodes L, Andrews J, Payne RC (2008) Functional anatomy and muscle moment arms of the pelvic limb of an elite sprinting athlete: the racing greyhound (Canis familiaris). J Anat 213:361-372

Zhang ZH, Yang Y (2013) Forelimb myology of the golden pheasant (Chrysolophus pictus). Int J Morphol 31:1482-1490

\section{Submit your next manuscript to BioMed Central and take full advantage of:}

- Convenient online submission

- Thorough peer review

- No space constraints or color figure charges

- Immediate publication on acceptance

- Inclusion in PubMed, CAS, Scopus and Google Scholar

- Research which is freely available for redistribution 